Research Article

\title{
Laccase immobilized on screen printed carbon electrode as quercetin biosensor
}

\begin{abstract}
Rapid electrochemical quercetin detection by oxidation of oxygen from laccase-quercetin enzymatic reaction from Trametes versicolor is proposed. Three different method for laccase enzyme immobilization on screen printed carbon electrode (SPCE) were compared for the development of quercetin biosensors. In this work, gluteraldehyde and nafion were deposited onto enzyme electrode surface and were evaluated by cyclic voltammetric and chronoamperometric. The measurements were performed in $0.05 \mathrm{M}$ acetate buffer $(\mathrm{pH} 5.0$ ). The modified biosensor for quercetin detection based on laccase/gluteraldehyde/SPCE gives highest sensitivity $\left(341.2 \mu \mathrm{AmM}^{-1} \mathrm{~cm}^{-2}\right)$ at concentration of laccase $\left(100 \mathrm{mgmL}^{-1}\right)$ and at applied potential $+0.2 \mathrm{~V}$. The range of detection is from 1.0 to $20.0 \mu \mathrm{M}\left(\mathrm{R}^{2}=0.99\right)$ with a detection limit of $3.74 \mu \mathrm{M}$ and response time of $2.45 \mathrm{~s}$
\end{abstract}

Volume 7 Issue I - 202 I

\author{
Suraya Mohd Saad, Norizan Ahmat, \\ Zainiharyati Mohd Zain \\ Electrochemical Material and Sensor Research Group, Malaysia
}

\begin{abstract}
Correspondence: Zainiharyati Mohd Zain, Electrochemical Material and Sensor Research Group, Faculty of Applied Sciences, Universiti Teknologi MARA, 40450 Shah Alam, Selangor, Malaysia,Email zainihar@uitm.edu.my
\end{abstract}

Received: December 3I, 2020 | Published: January 29, 2021

Keywords: biosensor, quercetin, SPCE, laccase, cyclic voltammetric, chronoamperometric

\section{Introduction}

Biosensors can be defined as an analytical device or system consisting of an immobilized biological material in intimate contact with a suitable transducer. Biosensors are smart alternative methods due to their special features such as selectivity, low expenditure, miniaturization, ease to use, time saving and simplicity of operation. The biological part namely called the sensing element that responds to the compound being measured is biological in nature. A specific biological reaction is converted by a transducer to produce a current response which is relative to the concentration of a substrate can be processed into a useable signal. ${ }^{1}$ In recent years, there are growing interests attaining the biologically active compounds from natural sources that lead to the development of biosensor. The protective effects of diets rich in tropical against diseases and certain cancers have been attributed partly to the antioxidants such as flavonoid because its shows variety of essential bioactivities. Studies on organic compounds that undergo bioactivity properties such as antioxidant, antiviral, and so on for medical benefits have become trend nowadays. This is due to the abundant species of plants which contains various polyphenols, terpenes and organic acids. ${ }^{2}$ Quercetin is a chemical compound from flavonol, one of the seven groups in the flavonoids family, a powerful antioxidant, and is regularly consumed by humans in edible fruits and vegetables at levels of up to $16 \mathrm{mg}$ per day as discussed elsewhere. ${ }^{3,4}$ Refer to Van Acker et $\mathrm{al}^{5}$ apart from flavonoids' therapeutic effects, quercetin is also an excellent scavenger of free radicals which benefits humans immensely, therefore much attention has been paid to both biological and physicochemical properties of quercetin over the past few decades.

The discovery on screen printed electrode (SPE) opens new paths in the field of sensors. SPE is an entrenched and simple technology for mass production of single electrode for biosensor application which applies electrochemical method providing convenience, simple and inexpensive approach. Many established research laboratories fabricate SPE for their own use and some companies produce mass SPE production that offer numerous designs with better quality. In this case, normally SPE manufacture provides the market with authentic characteristic such as different inks, substrates and design of SPE that have specific electrochemical behavior stated by Morrin ${ }^{6}$ Studies that had been carried out by Portaccio et $\mathrm{al}^{7}$ for the detection of Bisphenol A, reported that thionine was used as electrochemical mediator coupled with a nanostructured carbon black. By means of cyclic voltammetry, the interaction of thionine adsorbed on modified screen printed electrode with laccase/BPA reaction products has been studied. Besides that, in the review by Renedo et $\mathrm{al}^{8}$ discussed on SPE that had been widely used in many fields such as foods, pharmaceutical and environmental. Enzyme modified SPE and immunosensor are also extensively studied for analysis of metals, pesticides, phenolics, hormones, genetics, drugs, cholesterols and glucose. Therefore, the increasing need for specific sensors to enable fast routine measurements in many fields of analysis elevates SPE usage in biosensors application among researchers in various fields, such as food, medicines, agriculture and pollution monitoring. ${ }^{9}$

Enzyme electrode is one of the most intensively investigated biosensors because enzymes are highly selective and respond quickly to a specific substrate. Most widely used biosensor in SPE analysis of phenolic substances is based on immobilization enzymes such as peroxidase and tyroxidase. However, in this work using laccase as bio-recognition for detection of quercetin is being studied. The phenomenon of direct electron transfer (DET) in enzymes was first described for laccase by Fiera et al ${ }^{10}$ Electron transfer between analyte, an enzyme and electrode surface is fundamental process of electroanalytical methods. Laccase are copper-containing enzymes that has been received much attention from researchers in last decades due to its ability to catalyze the oxidation of a wide variety of organic and inorganic substrates including mono-, di-, and polyphenols, amino phenols, methoxy phenols, aromatic amines and ascorbate with the concomitant four electron reduction of oxygen to water, which make it very useful for application to several biotechnological processes. ${ }^{11,12}$ Studies by Odaci et $\mathrm{al}^{13}$ for detection of phenolic acid using laccase from Trametes versicolor was carried out on commercial oxygen electrode and ferrocene-modified screen-printed graphite electrodes. Proposed biosensors were analytically evaluated with real samples of human plasma and it is specific for a class of compounds, not for a single compound and this characteristic has been exploited to obtain an analytical device for a wide spectrum of phenolic compounds.

The measurement of the current resulting from the oxidation or reduction of electroactive species are based on chronoamperometric biosensors ${ }^{14}$ was implemented in this work. An electrochemical biosensor may be more attractive as compared to separation methods due simpler on-site analysis and fast response. technique. Cyclic voltammetric and amperometric enzymatic electrodes hold a leading position among presently available biosensor systems. 
These techniques offer huge information about analyte of interest. The selectivity of the amperometric devices is governed by the redox potential of the electroactive species present. ${ }^{15}$ Hence, the immobilization of laccase enzyme would improve the selectivity towards quercetin. The goal of this study is to develop a sensitive and fast carbon screen printed biosensor for quercetin analysis. In this work, SPCE was implemented in the development of the biosensor based on laccase using cyclic voltammetry and chronoamperometry for the detection of quercetin.

\section{Methodology}

\section{Chemical}

Quercetin dehydrate $\left(\mathrm{C}_{15} \mathrm{H}_{10} \mathrm{O}_{7}\right)$, calcium carbonate $\left(\mathrm{CaCO}_{3}\right)$, sodium sulphate $\left(\mathrm{Na}_{2} \mathrm{SO}_{4}\right)$, acetic acid $\left(\mathrm{C}_{2} \mathrm{H}_{4} \mathrm{O}_{2}\right)$, isopropanol $\left(\mathrm{C}_{3} \mathrm{H}_{8} \mathrm{O}\right)$, gluteraldehyde $25 \%\left(\mathrm{CH}_{2}\left(\mathrm{CH}_{2} \mathrm{CHO}\right)_{2}\right)$, Nafion $\left(\mathrm{C}_{7} \mathrm{HF}_{13} \mathrm{O}_{5} \mathrm{~S} \cdot \mathrm{C}_{2} \mathrm{~F}_{4}\right)$ and laccase (E.C. 1.10.3.2, 23.3 $\mathrm{Umg}^{-1}$ ) were purchased from SigmaAldrich. All chemicals used are analytical grade and were used as received without any further purification. All solutions were prepared with ultra-pure water of resistivity not less than $18.2 \mathrm{M} \Omega \mathrm{cm}^{-1}$.

\section{Apparatus}

The electrochemical measurements were performed using an Autolab potentiostat (PGSTAT) (Netherlands). All measurements were conducted using three electrode configurations consisting of carbon working electrode area of $4 \mathrm{~mm}$ in diameter, carbon-graphite counter electrode and $\mathrm{Ag} / \mathrm{AgCl}$ as reference. This commercially available SPE was utilized for comparison and sourced from Dropsens (Spain). The $\mathrm{pH}$ of acetate buffer and phosphate buffer were measured using $\mathrm{pH}$ meter (Mettler Toledo).

\section{Cleaning of SPCE surface}

It has been observed that cleaning of the SPCE is required before conducting any electrochemical performance. 1.0 M Sodium carbonate, $\mathrm{Na}_{2} \mathrm{CO}_{3}$ and $0.05 \mathrm{M}$ phosphate buffer saline solution, $\mathrm{PBS}$ were used as cleaning agent and was crucial in producing reproducible peak current and good surface active electrode. The cleaning process is performed by oxidising the electrode surface at $1.4 \mathrm{~V}$ for 90 seconds twice using sodium carbonate.

\section{Development of biosensors}

Three immobilization methods for the development of biosensors have been approached. Physical adsorption and cross-linked methods using gluteraldehyde (GA) and nafion were implemented respectively. Fabrication of biosensor by physical adsorption was carried out by air drying $20 \mathrm{mg} \mathrm{mL}^{-1}$ enzyme solution on surface electrode for 1 hour. Gluteraldehyde solution was prepared by dissolving $40 \mu \mathrm{L}$ GA (25\%) in ultra-pure water up to $10 \mathrm{~mL}$. The nafion solution was prepared by dissolving $20 \mu \mathrm{L}$ nafion in $65 \mu \mathrm{L}$ isopropanol and $15 \mu \mathrm{L}$ water solution. The same concentration of enzyme was applied for both cross-linked methods at $20 \mathrm{mgmL}^{-1}$ of laccase. The electrochemical measurements were done to study their sensitivity by mean of chronoamperometic detection of quercetin dehydrate in $0.05 \mathrm{M}$ acetate buffer $\mathrm{pH} 5$ as background electrolyte at working potential $+0.2 \mathrm{~V}$. Approximately, $2 \mu \mathrm{L}$ of enzyme solution was dropped onto working electrode to cover the area of working electrode and the buffer were purged with nitrogen gas to remove any dissolved oxygen in buffer solution.

\section{UV-Vis Spectrophotometry}

UV-Vis spectra of quercetin were recorded in the wavelength range from 190 to $600 \mathrm{~nm}$ using a UV-Vis spectrophotometer (PerkinElmer UV-Vis Lamda-35).

\section{Results and discussion}

\section{The electrochemical behavior of quercetin by cyclic voltammetry}

Some polyphenols have both oxidation and reduction peaks on their voltammograms showing reversibility on redox process. ${ }^{16}$ When the cyclic voltammogram for quercetin was investigated, it was realized that the top scan of the cyclic voltammogram represents the oxidation of quercetin and this is achieved by generating a cathodic current. Anodic current occurs by producing a peak at a particular electrode potential. On the reverse scan, reduced form of quercetin is oxidized back to its original form. In this situation, a positive peak potential is produced indicating to the anodic current value. A compound can be classified as powerful oxidation compound or reducing agent if oxidation takes place at lower potential. ${ }^{17}$

The oxidation of quercetin dehydrate studied by cyclic voltammetry demonstrated 3 oxidation peaks as in Figure 1, which occured at potentials $+0.20,+0.35$ and $+0.65 \mathrm{~V}$ (anodic peak potential, $\mathrm{E}_{\mathrm{pa}}$ ). Quercetin shows a peak at $+0.65 \mathrm{~V}$ due to the fact that, it contains hydroxyl group attached to the 3 position of B ring shown in Figure 3 . These three oxidation peaks are associated with oxidation of the 5 functional $\mathrm{OH}$ groups of quercetin. ${ }^{18}$ A reduction peak 4 at about + $0.18 \mathrm{~V}$ could also be seen corresponding to reduction of the oxidation products formed in peak 1 . This cyclic voltammogram clearly shows the reversible character of quercetin first electron transfer oxidation reaction. Therefore, a huge number of information on the mechanism of polyphenol oxidation can be obtained by investigating their cyclic voltammogram. Based on this information, the typical cyclic voltammogram of quercetin (Figure 1) is investigated to learn more about the electrochemical behaviour of quercetin (Figure 2). Quercetin has hydroxyl groups attached to the ring structures which may be electrochemically oxidised. Electrochemical studies reveal trends in the electron donating abilities of flavonoids. It showed that the catechol moiety is more easily oxidizable than the resorcinol group. Quercetin contains catechol moiety namely, the 3', 4'-dihydroxyl electron-donating group at ring $\mathrm{C}$, the oxidation of the catechol moiety occurs first at a low positive potential and is associated with peak 1 in the cyclic voltammogram. In quercetin, the $-\mathrm{OH}$ groups present on the $\mathrm{C}$ ring are responsible for the first oxidation peak. The oxidation process involves a two electron - two proton reversible reactions and forms o-quinone as shown in Figure 3.

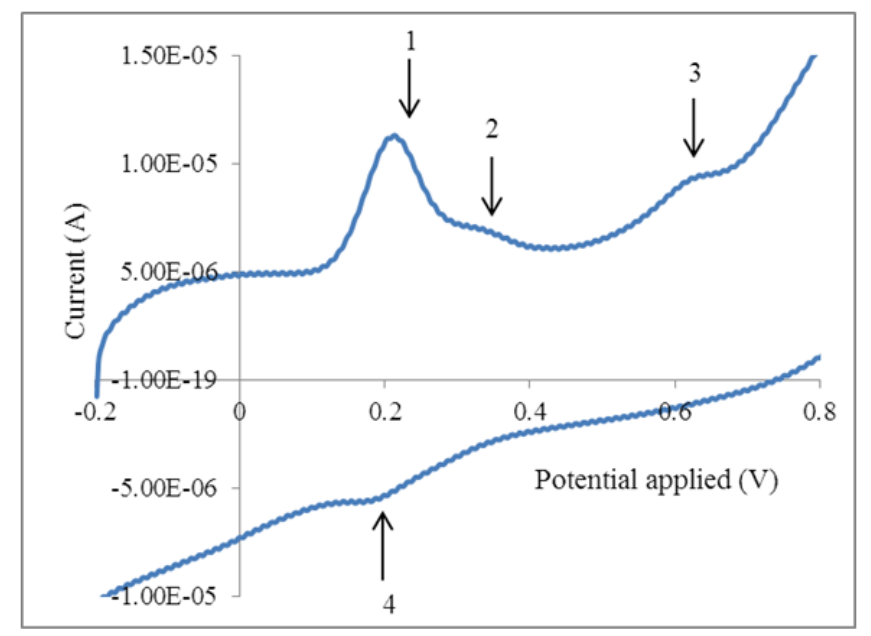

Figure I Cyclic voltammogram of $10 \mathrm{mM}$ quercetin dehydrate in acetate buffer $\mathrm{pH} 5$ on $0.126 \mathrm{~cm}^{2}$ electrode area. Scan rate of $0.1 \mathrm{Vs}^{-1}$. 
<smiles>O=c1c(O)c(-c2ccc(O)c(O)c2)oc2cc(O)cc(O)c12</smiles>

Figure 2 Chemical structure of quercetin dehydrate.

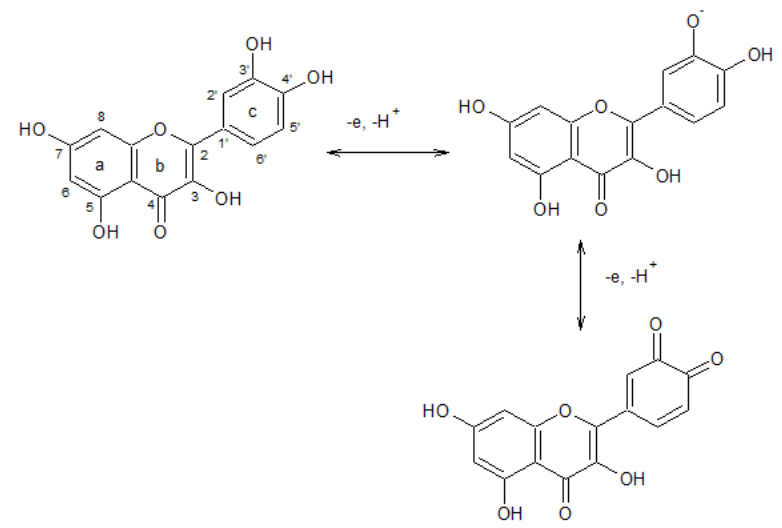

Figure 3 Reversibility of oxidation-reduction process of quercetin to form o-quinone. ${ }^{19}$

\section{Determination of biosensor sensitivity chronoamperometry for detection of quercetin}

Enzyme loading study showed the amount of sufficient enzyme concentrations that resulted in the significant sensitivities of the developed quercetin biosensor. Table 1 shows the sensitivity, regression coefficient $\left(\mathrm{R}^{2}\right)$, maximum current at saturation $\left(\mathrm{V}_{\max }\right)$, Michaelismenten constant $\left(\mathrm{K}_{\mathrm{M}}\right)$ and limit of detection (LOD) for enzyme loading study. This study was performed by chronoamperometric at applied potential $+0.2 \mathrm{~V}$ and the enzyme was deposited onto electrode surface by physical adsorption at concentration ranging from 20 to $100 \mathrm{mg} \mathrm{mL}{ }^{-1}$. The result shows that $100 \mathrm{mgmL}^{-1}$ gives higher sensitivity and $\mathrm{V}_{\text {max }}$ at $341.2 \mu \mathrm{AmM}^{-1} \mathrm{~cm}^{-2}$ and $2.0 \mu \mathrm{A}$ respectively. The modifications on electrode surface were also investigated by using nafion and gluteraldehyde. Table 2 shows the enormous different between both architectures in the same enzyme concentration at $20 \mathrm{mgmL}^{-1}$ and GA offers better sensitivity than nafion at $26.61 \mu \mathrm{A}$ $\mathrm{mM}^{-1} \mathrm{~cm}^{-2}$. This is due to effect of nafion as the polymer that has been used as a proton conductor for proton exchange membrane. ${ }^{20}$ Nafion also have hydrophilic properties to be selective to cation charge. ${ }^{21}$ This resemblance to a semi-infinite diffusion process was consistent with the slow charge transport in nafion. ${ }^{22}$ Therefore, the employment of Nafion is actually to enhance the selectivity of phenol not the sensitivity. As a result, this membrane gives different sensitivity and kinetic constant values.

\section{Calibration by UV-Vis Spectrophotometry}

In comparison, the detection of quercetin was examined by UV-Vis spectrophotometry. Two characteristic absorption bands of quercetin were present at 243 and $369 \mathrm{~nm}$ and the calibration graph was carried out at maximum adsorption wavelength, $\lambda_{369}$ shown in Figure 4 . Based on analysis, it can be concluded that the detection of quercetin using UV-Vis spectrophotometer takes longer time analysis and consumed lots of solvent compared to biosensor technique.

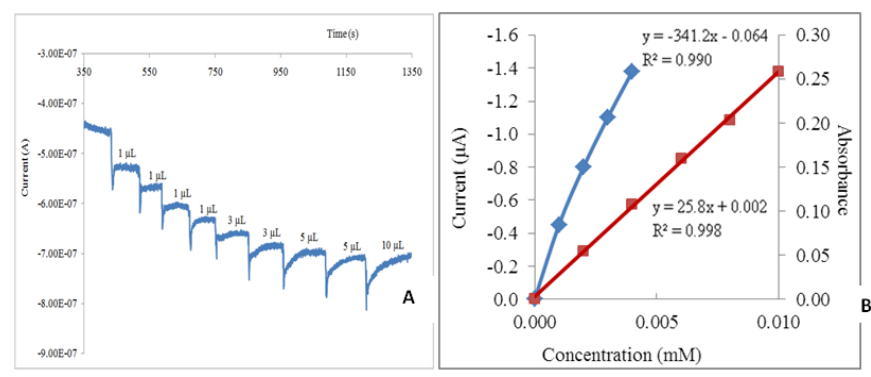

Figure 4 Chronoamperomogram of quercetin (A) and calibration graph (B) of current $(\Delta)$ and absorbance $(\square)$ towards concentration range from 2, 4, 6,8 and $10 \mu \mathrm{M}$ accordingly.

Table I Quercetin based on concentration immobilized on SPCE

\begin{tabular}{|c|c|c|c|c|c|}
\hline Enzyme loading $\left(\mathrm{mg} \mathrm{mL}^{-1}\right)$ & 20 & 40 & 60 & 80 & 100 \\
\hline Sensitivity $\left(\mu \mathrm{A} \mathrm{mM}^{-1} \mathrm{~cm}^{-2}\right)$ & 4.1 & 193.5 & 182.9 & 190.7 & 341.2 \\
\hline $\mathrm{R}^{2}$ & 0.987 & 0.949 & 0.990 & 0.991 & 0.990 \\
\hline$V_{\max }(\mu \mathrm{A})$ & 0.42 & 1.75 & 0.55 & 0.80 & 2.00 \\
\hline$K_{M}(\mu M)$ & 48.30 & 4.20 & 1.40 & 0.80 & 2.40 \\
\hline Limit of detection (mM) & 3.19 & 3.12 & 3.10 & 3.49 & 3.74 \\
\hline
\end{tabular}

Table 2 Quercetin based on laccase $\left(20 \mathrm{mg} \mathrm{mL}^{-1}\right)$ immobilized by gluteraldehyde and nafion on SPCE

\begin{tabular}{llll}
\hline Immobilization & $\begin{array}{l}\text { Physical } \\
\text { adsorption }\end{array}$ & $\begin{array}{l}\text { Nafion } \\
(\mathbf{I} .0 \%)\end{array}$ & $\begin{array}{l}\text { Gluteraldehyde } \\
\mathbf{( 0 . 1 \% )}\end{array}$ \\
\hline $\begin{array}{l}\text { Sensitivity }(\mu \mathrm{A} \\
\left.\mathrm{mM}^{-1} \mathrm{~cm}^{-2}\right)\end{array}$ & 4.13 & 4.94 & 26.61 \\
$\mathrm{R}^{2}$ & 0.987 & 0.997 & 0.971 \\
$\mathrm{~V}_{\max }(\mu \mathrm{A})$ & 0.415 & 0.135 & 0.462 \\
$\mathrm{~K}_{M}(\mathrm{mM})$ & 0.048 & 0.028 & 0.007 \\
$\mathrm{LOD}(\mathrm{mM})$ & 3.174 & 3.895 & 3.420 \\
\hline
\end{tabular}

\section{Conclusion}

A biosensor based on laccase/gluteraldehyde immobilized on SPCE has good sensitivity and response time for quercetin detection. A range of detection from 1 to $20 \mu \mathrm{M}\left(\mathrm{R}^{2}=0.99\right)$ with a detection limit of $3.74 \mu \mathrm{M}$ and response time of $2.45 \mathrm{~s}$ were observed. Thus, the development of laccase immobilized on screen printed carbon electrode was proven to be sensitive and fast for the detection of quercetin.

\section{Acknowledgements}

We are grateful to Malaysian Toray Science Fund (2011) and Research Excellence Fund (600-RMI/DANA 5/3/SG(3/2012)) in funding this project.

\section{Conflicts of interest}

The authors declare that there is no conflict of interest.

\section{References}

1. Scott AO. Biosensors for Food Analysis. UK. The Royal Society of Chemistry; 1998. 
2. Herrmann K. Critical reviews in food science and nutrition 1989;28(4):315-347.

3. Manach C, Morand C, Crespy V, et al. Quercetin is recovered in human plasma as conjugated derivatives which retain antioxidant properties. FEBS Letter. 1998;426:331-336.

4. Prior RL. Absorption and Metabolism of Anthocyanins: Potential Health Effects. In Proceedings of the 4th International Phytochemical Conference. Pomona, CA, USA. Calif State Polytechn University; 2122 October 2002.

5. Van Acker SA, Tromp MN, Haenen GR, et al. Flavonoids as scavengers of nitric oxide radical. Biochemical and Biophysical Research Communications. 1995;214:755-759.

6. Morrin A, Killard AJ, Smyth MR. Electrochemical Characterization of Commercial and Home-Made Screen-Printed Carbon Electrodes. Analytical Letters. 2003;36(9):2021-2039

7. Portaccio M, Di Tuoro D, Arduini F, et al. Laccase biosensor based on screen-printed electrode modified with thionine-carbon black nanocomposite, for Bisphenol A detection. Electrochimica Acta. 2013;109:340-347.

8. Renedo OD, Lomillo MAA, Mart'inez MJA. Review: Recent developments in the field of screen-printed electrodes and their related applications. Talanta. 2007;73:202-219.

9. D’Orazio P. Biosensor in Clinical chemistry. Clinical Chimical Acta. 2003;334:41-69.

10. Freire RS, Ferreira MMC, Duran N, et al. Dual amperometric biosensor device for analysis of binary mixtures of phenols by multivariate calibration using partial least squares. Analytica Chimica Acta. 2003;485:263-269.

11. Gianfreda L, Sannino F, Filazzola MT, et al. Catalytic behavior and detoxifying ability of a laccase from the fungal strain Cerrena unicolor. Journal of Molecular Catalysis B: Enzymatic. 1998;4(1-2):13-23.
12. Galhaup C, Goller S, Peterbauer CK, et al. Characterization of the major laccase isoenzyme from Trametes pubescens and regulation of its synthesis by metal ions. Microbiology. 2002;148:2159-2169.

13. Odaci D, Timur S, Pazarlioglu N, et al. Determination of phenolic acids using Trametes versicolor laccase. Talanta. 2007;71:312-317.

14. Vastarella W. Enzyme Modified Electrodes in Amperometric Biosensors. University of Degli Studi di Bari; 2001.

15. Freire RS, Pessoa CA, Mello LD, et al. Direct electron transfer: an approach for electrochemical biosensors with higher selectivity and sensitivity. Journal Brazil Chemical Society. 2003;14:230-243.

16. Filipiak M. Electrochemical analysis of polyphenolic compounds. Analytical Sciences. 2001;17:1667-1670.

17. Kilmartin PA, Hsu CF. Characterisation of polyphenols in green, oolong, black teas and in coffee using cyclic voltammetry. Food Chemistry. 2003;82:501-512.

18. Brett AMO, Ghica ME. Electrochemical Oxidation of Quercetin. Electroanalytical. 2003;15:22.

19. Pourcel L, Routaboul J, Cheynier V, et al. Flavonoid oxidation in plants: from biochemical properties to physiological functions. Trends in Plant Science. 2007;12:29-36.

20. Fan ZH, Harrison DJ. Permeability of glucose and other neutral species through recast perfluorosulfonated nanomer films. Analytical Chemistry. 199;64(11):1304.

21. Kim MA, Lee WY. Amperometric phenol biosensor based on solgel silicate/nafion composite film. Analytical Chemistry Acta. 2003;479:143-150.

22. Chen HY, Ju HX, Xun YG. The properties of the methylene blue/Nation modified microcylinder carbon fiber electrode and its application for the determination of hemoglobin by heterogeneous catalytic reaction. Analytical Chemistry. 1994;66:4538. 